\title{
Three-Dimensional Computed Tomography Reconstruction Unmasks Shunt Disconnection in a Child
}

\author{
Jignesh K. Tailor (D), Ian C. Coulter, Michael C. Dewan, Helen M. Branson, \\ Peter B. Dirks, James T. Rutka
}

Keywords: Hydrocephalus, Shunt disconnection, 3D reconstruction, Multidetector CT, Reformats

doi:10.1017/cjn.2020.110

Can J Neurol Sci. 2020; 47: 826-827

An 18-month-old patient with complex postinfectious hydrocephalus presented with suspected shunt malfunction. The infant was vomiting intermittently for over a month, but her clinical appearance was reassuring. She was alert with no focal neurological deficits. The fontanelle was closed and papilledema was absent. Cranial imaging demonstrated ventriculomegaly (Figure 1A) but prior cross-sectional imaging was unavailable for comparative review. The shunt $\mathrm{X}$-rays and axial computerized tomography (CT) did not reveal an obvious shunt disconnection (Figure 1B). We were unable to aspirate cerebrospinal fluid from the shunt, but her symptoms resolved spontaneously soon after admission. A diagnosis of arrested hydrocephalus and a viral illness was suspected. She re-presented with emesis 7 days later. Again, her clinical status was reassuring with no impairment of consciousness or signs of raised intracranial pressure. A repeat CT scan showed stable ventriculomegaly and no obvious shunt disconnection was apparent on repeat X-rays.

We elected to explore the shunt in the operating room the day after admission. Intraoperatively, an unexpected disconnection was identified between the proximal ventricular catheter and shunt valve. Correction of this problem quickly led to resolution of the patient's symptoms. We re-reviewed the preoperative imaging at initial presentation and during her repeat admission but could not visualize the disconnection (Figure 1A and B). However, we retrospectively obtained $3 \mathrm{D}$ reconstructions of the CT scans, which clearly demonstrated the disconnection (Figure 2). This case emphasizes the value of obtaining 3D-CT reconstructions in the context of suspected shunt malfunction, especially in the pediatric patient who may not exhibit overt clinical or radiological signs. Earlier identification of the disconnection via 3D-CT imaging may have enhanced decision making, avoided a discharge and readmission, and facilitated prompter treatment.

Shunt disconnection is the cause of malfunction in approximately $10 \%$ of cases. ${ }^{1}$ Diagnosing shunt disconnection with shunt series X-rays may prove difficult as the disconnection may be subtle, as in our case, and the shunt may still be partially functional which can manifest as inconsistent and intermittent symptoms. ${ }^{2,3}$ The negative predictive value of shunt series $\mathrm{X}$-rays is only $22 \% .^{4} 3 \mathrm{D}$ visualization of the shunt by reconstruction of a multidetector CT scan provides much better clarity of shunt components. ${ }^{3}$ These $3 \mathrm{D}$ reformats can be easily generated from the original CT dataset from a multidetector CT available in most imaging departments today and do not require any increased radiation dose.

In summary, 3D-CT reconstructions retrospectively proved to be diagnostic of a subtle shunt disconnection in a child with ambiguous clinical and radiological signs of shunt malfunction. In our institution, patients with suspected shunt malfunction who have CT brain imaging on admission are now receiving routine radiological evaluation with $3 \mathrm{D}-\mathrm{CT}$ reconstructions to facilitate the detection of obscure shunt fractures and disconnections.

\section{FUNDING}

No research funding was received for this work. J.T. received a Wellcome Trust Fellowship Award for his training at The Hospital for Sick Children.

\section{Conflicts of Interest}

The authors declare no conflicts of interest.

\section{STATEMENT OF AUTHORSHIP}

J.T., I.C., and M.D. contributed to the concept of this article. J.T. and I.C. drafted the manuscript and prepared figures. H.B. provided imaging data. M.D., H.B., P.D., and J.R. contributed to the final manuscript with edits and comments.

\section{Ethics Approval}

This is a case study with informed consent obtained by parent of all patients being reported on. The Research Ethics Committee has confirmed that no ethical approval is required for case studies in which patient and/or parent consent has been obtained.

\section{Consent to Participate}

Informed consent was obtained from the legal guardian of all patients included in this report.

From the Division of Neurosurgery, The Hospital for Sick Children, University of Toronto, Toronto, Ontario, Canada (JKT, ICC, MCD, PBD, JTR); and Division of Diagnostic Imaging, The Hospital for Sick Children, Toronto, Ontario, Canada (HMB) Received April 26, 2020. Final Revisions Submitted May 28, 2020. Date of Acceptance May 29, 2020.

Correspondence to: James Rutka MD PhD, Division of Neurosurgery, The Hospital for Sick Children, Toronto, Ontario, Canada. Email: James.rutka@sickkids.ca 


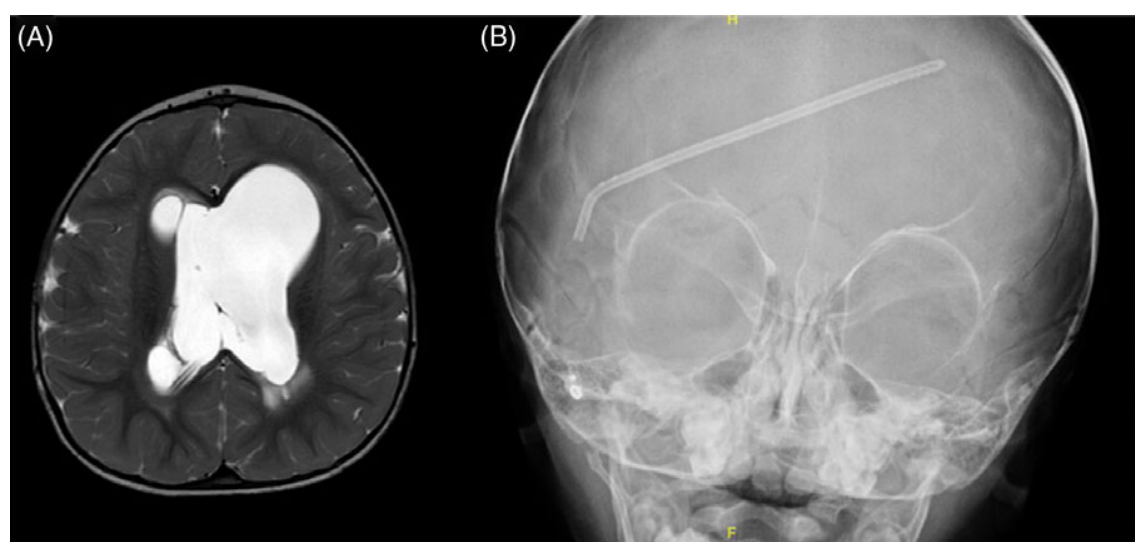

Figure 1: (A) Axial T2 MRI showing ventriculomegaly and encysted ventricles. (B) Skull X-ray showed no obvious disconnection.

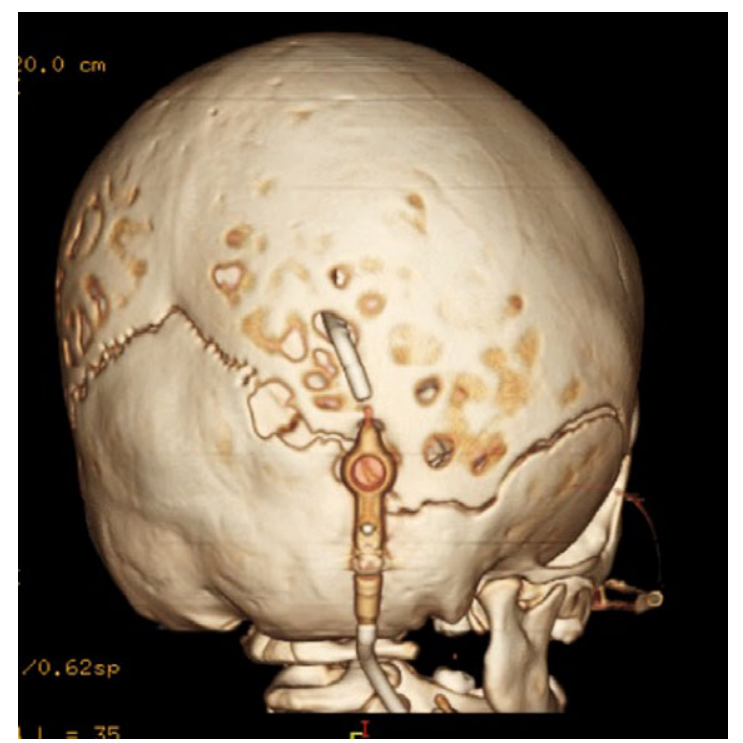

Figure 2: $3 D$ reconstruction of CT head scan prior to shunt exploration showed clear disconnection of the proximal catheter from the shunt valve.

\section{Consent for Publication}

Informed consent for publication was obtained from the legal guardian of all patients included in this report.

\section{REFERENCES}

1. Erol FS, Ozturk S, Akgun B, Kaplan M. Ventriculoperitoneal shunt malfunction caused by fractures and disconnections over 10 years of follow-up. Child's Nerv Syst. 2017;33(3):475-81.

2. Kazan S, Açikbaş C, Rahat Ö, Tuncer R. Proof of the patent subcutaneous fibrous tract in children with V-P shunt malfunction. Child's Nerv Syst. 2000;16(6):351-6

3. Kadom N, Narayanan S, Trofimova A. Pearls in pediatric shunted brain CT evaluation. J Pediatr Neuroradiol. 2015;3(3):107-20.

4. Zorc JJ, Krugman SD, Ogborn J, Benson J. Radiographic evaluation for suspected cerebrospinal fluid shunt obstruction. Pediatr Emerg Care. 2002;18(5):337-40. 